\title{
Ventilatory Sensitivities of Peripheral and Central Chemoreceptors of Young Piglets to Inhalation of $\mathrm{CO}_{2}$ in Air
}

\author{
J. G. WOLSINK, A. BERKENBOSCH, J. DeGOEDE, AND C. N. OLIEVIER \\ Department of Physiology, University of Leiden, 2300 RC Leiden, The Netherlands
}

\begin{abstract}
In 20 piglets aged 2-12 d (mean $6.8 \mathrm{~d}$ ) and anesthetized with $\alpha$-chloralose-urethane, we investigated the contribution of the peripheral and central chemoreceptors to the ventilatory response to inhalation of $\mathrm{CO}_{2}$ in air. For this purpose we used the dynamic end-tidal forcing technique, applying square-wave changes in end-tidal $\mathrm{CO}_{2}$ tension of $1.5-2.0 \mathrm{kPa}$ at a constant end-tidal $\mathrm{O}_{2}$ tension of $15 \mathrm{kPa}$. Each response, measured on a breath-to-breath basis, was separated into a fast peripheral and a slow central component by fitting the sum of two exponentials to the measured ventilation. Each component was characterized by a $\mathrm{CO}_{2}$ sensitivity, a time constant, a time delay, and an apneic threshold. The results showed that in 2- to 12-d-old piglets the peripheral chemoreceptors are responsive to $\mathrm{CO}_{2}$ during air breathing. The contribution of the peripheral chemoreceptors in mediating the response to $\mathrm{CO}_{2}$ averaged $30 \pm 10 \%$. Within this age range we could not demonstrate a significant correlation of the parameters characterizing the dynamic ventilatory response to $\mathrm{CO}_{2}$ with postnatal age. (Pediatr Res 30: 491-495, 1991)
\end{abstract}

\section{Abbreviations}

DEF, dynamic end-tidal forcing

PETCO $_{2}$, end-tidal partial $\mathrm{CO}_{2}$ pressure

PETO $_{2}$, end-tidal partial $\mathrm{O}_{2}$ pressure

$\mathrm{S}, \mathrm{CO}_{2}$-slope, the slope of the ventilatory response to $\mathrm{CO}_{2}$ $\mathrm{S}_{\mathrm{p}}$, peripheral ventilatory $\mathrm{CO}_{2}$ sensitivity

$\mathrm{S}_{c}$, central ventilatory $\mathrm{CO}_{2}$ sensitivity

$\mathrm{S}_{\mathrm{p}} / \mathrm{S}$, the ratio of the peripheral $\mathrm{CO}_{2}$ sensitivity to (total)

$\mathrm{CO}_{2}$-slope

$B$, apneic threshold

$\mathrm{PaO}_{2}$, arterial $\mathrm{O}_{2}$ tension

The role played by the peripheral and central chemoreceptors in the control of breathing shortly after birth has received much attention. Most studies in this field have been directed to the peripheral chemoreceptors monitored by the hypoxic and hyperoxic ventilatory response. In kittens, lambs, and rats immediately after birth, this response is weak or absent, indicating a feeble respiratory drive from the peripheral chemoreceptors. This is probably due to the rise in $\mathrm{PaO}_{2}$ that occurs when air breathing is established ( $1-3)$. Over the next $1-3 \mathrm{~d}$ after birth, the peripheral chemoreceptors undergo a resetting, i.e. the range of hypoxic sensitivity is changed from the fetal toward the more adult range of blood gas tensions $(4,5)$. From that time on, they actively

Received September 11, 1990; accepted April 6, 1991.

Correspondence and reprint requests: J. G. Wolsink, Department of Physiology, P. O. Box 9604,2300 RC Leiden, The Netherlands.

Supported by the Netherlands Organization for Scientific Research (NWO), Grant GB-MW 900-5 10-079. control the ventilation. Studies from Belenky et al. (6) and Bureau and Bégin (7) suggest that in the lamb the peripheral chemoreceptors continue to maturate after the resetting in the first $2 \mathrm{~d}$ after birth. The ventilatory response to hypoxia and hyperoxia as well as the response to potassium cyanide showed an increase until about $10 \mathrm{~d}$ of life. In this paper, animals in which a major part of the peripheral chemoreceptor resetting has occurred (age at least 2 d) will be called young animals to distinguish them from newborns.

In contrast to the amount of information about the hypoxic and hyperoxic ventilatory response, studies of the ventilatory response to $\mathrm{CO}_{2}$ in young animals are sparse. The question of whether the carotid chemoreceptors in young animals contribute to the ventilatory response to $\mathrm{CO}_{2}$ inhalation during air breathing has not been answered. There is some indirect information from steady state techniques in which the $\mathrm{CO}_{2}$-slope is compared before and after denervation of the peripheral chemoreceptors. In lambs 1 to $10 \mathrm{~d}$ old (8), denervation of the carotid bodies led to a slight decrease in $\mathrm{CO}_{2}$-slope, an increased latency time, and a slower rate of rise of ventilation in response to inhaled $\mathrm{CO}_{2}$, suggesting that at least a part of the $\mathrm{CO}_{2}$ response was dependent on the fast-responding peripheral chemoreceptors. Furthermore, an age-related change in $\mathrm{CO}_{2}$-slope could not be detected. In monkeys the $\mathrm{CO}_{2}$-slope increased between 2 and $21 \mathrm{~d}(9)$. Human infants showed an increase in $\mathrm{CO}_{2}$-slope of $62 \%$ from 2 to $27 \mathrm{~d}$ of postnatal life (10). However, to the best of our knowledge there are no studies about to what extent the peripheral and central chemoreceptors contribute to the ventilatory response to $\mathrm{CO}_{2}$ in young animals during air breathing. The DEF technique is probably the only way to get information on this issue noninvasively $(11,12)$. With this technique the end-tidal $\mathrm{PCO}_{2}$ is forced to follow a prescribed pattern in time at a constant end-tidal $\mathrm{O}_{2}$ tension. The ventilatory response, measured on a breath-tobreath basis, is separated into a fast peripheral and a slow central component using a two-compartment model $(12,13)$. The measured end-tidal $\mathrm{CO}_{2}$ is used as input function.

The technique has been successfully applied in anesthetized adult cats (12) and awake human beings (14). It was our purpose to investigate the relative contribution of the peripheral and central chemoreceptors in newborns as well as young animals using the DEF technique. In a first approach, however, young piglets were used in which a major part of the peripheral chemoreceptor resetting would have occurred, so it is plausible to expect a sizeable contribution of the peripheral chemoreceptors to the ventilatory response to $\mathrm{CO}_{2}$.

\section{MATERIALS AND METHODS}

Experiments were performed on 20 anesthetized piglets of either sex. The use of the animals was reviewed and approved by the Ethical Committee for Animal Experiments of the University of Leiden. Animals ranged in age from 2 to $12 \mathrm{~d}$ (mean $6.8 \pm 3.1 \mathrm{~d}$ ) with a mean body weight of $2.7 \pm 0.6 \mathrm{~kg}$. Anesthesia 
was induced with $5-7.5 \mathrm{mg} \cdot \mathrm{kg}^{-1}$ zolazepam and tiletamine (Zoletil; Virbac Laboratories, France) intramuscularly followed by halothane inhalation. The right femoral vein was cannulated and $7-25 \mathrm{mg} \cdot \mathrm{kg}^{-1} \alpha$-chloralose and $35-125 \mathrm{mg} \cdot \mathrm{kg}^{-1}$ urethane were slowly administered. Then the volatile anesthetic was withdrawn. About an hour later an infusion of a mixture of zolazepam, tiletamine, $\alpha$-chloralose, and urethane was started at a rate of $0.5-5 \mathrm{mg} \cdot \mathrm{kg}^{-1} \cdot \mathrm{h}^{-1}$ each of zolazepam and tiletamine, $0.5-2$ $\mathrm{mg} \cdot \mathrm{kg}^{-1} \cdot \mathrm{h}^{-1} \alpha$-chloralose, and $2.5-10 \mathrm{mg} \cdot \mathrm{kg}^{-1} \cdot \mathrm{h}^{-1}$ urethane. The level of anesthesia was periodically evaluated by noting the eyelid reflex and the response to pain stimulation. The trachea was cannulated through a tracheostomy and connected to a Tpiece. One arm of the T-piece received a flow of gas from a gas mixing system in excess of the inspiratory demand. The endtidal $\mathrm{CO}_{2}$ and $\mathrm{O}_{2}$ could be set at any desired level by manipulating the inspired $\mathrm{CO}_{2}$ and $\mathrm{O}_{2}$ concentrations by servo control with a computer. The right femoral artery was cannulated to measure arterial pressure. In 15 piglets, after cannulation of the left femoral artery, an extracorporeal circuit was connected between the cannulated left femoral artery and one lumen of a doublelumen catheter lying in the right femoral vein.

Measurements. Inspiratory and expiratory flows were measured using a Fleisch no. 0 pneumotachograph connected to a differential pressure transducer (Statham, Cambridge, MA). The flow signal was electronically integrated to yield a volume signal. The $\mathrm{CO}_{2}$ concentration in the respiratory air was measured with the aid of a capnograph (Gould Godart MK2, The Netherlands) and the $\mathrm{O}_{2}$ concentration with a fast oxygen analyzer $\left(\mathrm{Jaeger} \mathrm{O}_{2}\right.$ test, Germany). The arterial $\mathrm{pH}$, arterial $\mathrm{CO}_{2}$, and $\mathrm{PaO}_{2}$ were continously measured with electrodes in the extracorporeal circuit. Blood pressure was measured with a pressure transducer. The rectal temperature was monitored with a thermistor and controlled within $1.0^{\circ} \mathrm{C}$ with an infrared lamp and a heating pad, but varied from $37.2-40.0^{\circ} \mathrm{C}$ between piglets. All signals were recorded on polygraphs, digitized (sample frequency $100 \mathrm{~Hz}$ ), processed by a PDP 11/23 minicomputer, and stored on a disk. The tidal volume, inspiratory time, expiratory time, inspiratory ventilation, respiratory frequency, end-tidal $\mathrm{CO}_{2}$, and end-tidal $\mathrm{O}_{2}$ were stored on a breath-to-breath basis. Details of the methods have been published previously (15)

Experimental protocol. After a period of surgical preparation and stabilization (about $4.5 \mathrm{~h}$ in total), the measurements were started. Each DEF experiment consisted of an episode of steady state ventilation of approximately 2 min during which the $\mathrm{PETCO}_{2}$ was held slightly above its resting value by giving small amounts of $\mathrm{CO}_{2}$ in the inspired air. The PETCO 2 was then elevated $1.5-2.0 \mathrm{kPa}$ within one or two breaths, maintained constant for a period of 5-8 $\mathrm{min}$, and then returned stepwise to the original value and kept constant for a further 5-8 min (Fig. 1). During this maneuver, the $\mathrm{PETO}_{2}$ was held constant at 15 $\mathrm{kPa}$. In each animal at least three DEF runs were performed.

$D E F$ technique and data analysis. For the analysis of the breath-to-breath data obtained in the DEF runs, we used a twocompartment model proposed by Bellville et al. (13). In this model the dynamics of the ventilatory responses of the central and peripheral chemoreflex loops are described by:

$$
\tau_{c} d \dot{V}_{c} / d t+\dot{V}_{c}=S_{c}\left[P C_{C O}\left(t-T_{c}\right)-B\right]
$$

and

$$
\tau_{\mathrm{p}} \mathrm{d} \dot{\mathrm{V}}_{\mathrm{p}} / \mathrm{dt}+\dot{\mathrm{V}}_{\mathrm{p}}=\mathrm{S}_{\mathrm{p}}\left[\operatorname{PETCO}_{2}\left(\mathrm{t}-\mathrm{T}_{\mathrm{p}}\right)-\mathrm{B}\right] .
$$

The time constants of the central and peripheral ventilatory responses are denoted by $\tau_{c}$ and $\tau_{p}$, respectively. $\dot{V}_{c}$ and $\dot{V}_{p}$ are the central and peripheral parts of the response; $S_{c}$ and $S_{p}$, the central and peripheral ventilatory $\mathrm{CO}_{2}$ sensitivities; and $\mathrm{T}_{c}$ and $\mathrm{T}_{\mathrm{p}}$, the times needed to transport the $\mathrm{PCO}_{2}$ disturbance from the lungs to the central and peripheral chemoreceptive structures. The offset $\mathrm{B}$ represents the apneic threshold or extrapolated $\mathrm{PETCO}_{2}$ of the steady state ventilatory response to $\mathrm{CO}_{2}$ at zero ventilation, and the total $\mathrm{CO}_{2}$ sensitivity $S$ equals $\mathrm{S}_{\mathrm{p}}+\mathrm{S}_{\mathrm{c}}$. To model the central time constant of the on-transient to be different from that of the off-transient, $\tau_{\mathrm{c}}$ is written as:

$$
\tau_{\mathrm{c}}=\tau_{\mathrm{on}} \cdot \mathrm{x}+(1-\mathrm{x}) \tau_{\text {off }}
$$

In this equation, $\mathrm{x}=1$ when $\mathrm{PETCO}_{2}$ is high (on-transient) and $\mathrm{x}=0$ when $\mathrm{PETCO}_{2}$ is low (off-transient).

In most experiments a small drift in the ventilation was present. Therefore, we included a drift term C.t, so that the total ventilation $\left(\dot{\mathrm{V}}_{\mathrm{I}}\right)$ is given by:

$$
\dot{\mathrm{V}}_{\mathrm{l}}(\mathrm{t})=\dot{\mathrm{V}}_{\mathrm{c}}(\mathrm{t})+\dot{\mathrm{V}}_{\mathrm{p}}(\mathrm{t})+\mathrm{C} \cdot \mathrm{t}
$$

The parameters of the model were estimated by fitting the data with a least squares method. To obtain optimal time delays, a "grid search" was applied. All combinations of $T_{p}$ and $T_{c}$ with increments of $1 \mathrm{~s}$ and $T_{c} \geq T_{p}$ were tried until a minimum in the residual sum of squares was found. The minimal time delays were, somewhat arbitrarily, chosen to be $1 \mathrm{~s}$, and $\tau_{\mathrm{p}}$ was constrained to be at least $0.3 \mathrm{~s}$.

\section{RESULTS}

Figure 1 shows a computer plot of the $\mathrm{PO}_{2}$ and $\mathrm{PCO}_{2}$ in the tracheal gas and breath-to-breath ventilation in a typical example of a DEF experiment on a piglet $3 \mathrm{~d}$ of age. In response to the step increase in $\mathrm{PETCO}_{2}$, the ventilation increased shortly thereafter. In 17 piglets this ventilatory increase was brought about by an increase in both tidal volume and respiratory frequency. In three piglets, only tidal volume increased after raising the $\mathrm{PETCO}_{2}$. A total of $76 \mathrm{DEF}$ runs were analyzed. Figure 2 shows the computer output of the analysis of the breath-to-breath data of the DEF run shown in Figure 1. In 74 of the 76 runs, a fast and a slow component were obtained. The analysis of two of the three runs in one 9-d-old piglet yielded no fast component. Most animals showed at regular time intervals an augmented breath or sigh with a tidal volume of about 2 times the tidal volume of "normal breaths." The frequency of the sighs was rather high (about 2-3 per min). These sighs seem to be a characteristic feature of the ventilatory pattern in anesthetized young piglets, and we did not remove them from the data set. As a result of a sigh, the $\mathrm{PETCO}_{2}$ of the next breath was appreciably lower especially at the low $\mathrm{PETCO}_{2}$ level where the difference between inspired and expired $\mathrm{PCO}_{2}$ is maximal. However, inasmuch as the model parameters were estimated using the actual $\mathrm{PETCO}_{2}$ as input, these disturbances in $\mathrm{PETCO}_{2}$ are taken into account, as can be seen in Figure 2.

We looked for a correlation between the estimated parameters and age. Figure 3 shows the relation between four of these parameters $\left(\mathrm{S}_{\mathrm{p}}, \mathrm{S}_{\mathrm{c}}, \mathrm{B}\right.$, and $\left.\mathrm{S}_{\mathrm{p}} / \mathrm{S}\right)$ and age. No significant correlation was found between any of these parameters and age, although $S_{p} / S$ tended to increase and $S_{c}$ tended to decrease with age. For summarizing purposes, the means of the means per piglet of all the estimated parameters of the individual DEF runs together with their $\mathrm{SD}$ are listed in Table $1 . \mathrm{S}_{\mathrm{c}}$ and $\mathrm{S}_{\mathrm{p}}$ were normalized to body weight and expressed per $\mathrm{kg}$.

\section{DISCUSSION}

A survey of the literature reveals that the relative contribution of the central and peripheral chemoreceptors in the control of breathing in young animals has not been assessed satisfactorily $(16,17)$. In this study we used the noninvasive DEF technique in young piglets to separate the ventilatory response to $\mathrm{CO}_{2}$ into a peripheral and central component without the need of interrupting neural pathways as in denervation techniques. To separate the ventilatory response to inhalation of $\mathrm{CO}_{2}$ in air $\left(\mathrm{PETO}_{2}\right.$ $15 \mathrm{kPa}$ ) into a peripheral and a central component, the difference in speed of response of both chemoreflex loops and the difference in transport time of the $\mathrm{CO}_{2}$ challenge to the site of action is utilized. In previous studies $(12,14)$, we have shown that in awake human beings as well as in anesthetized animals the 


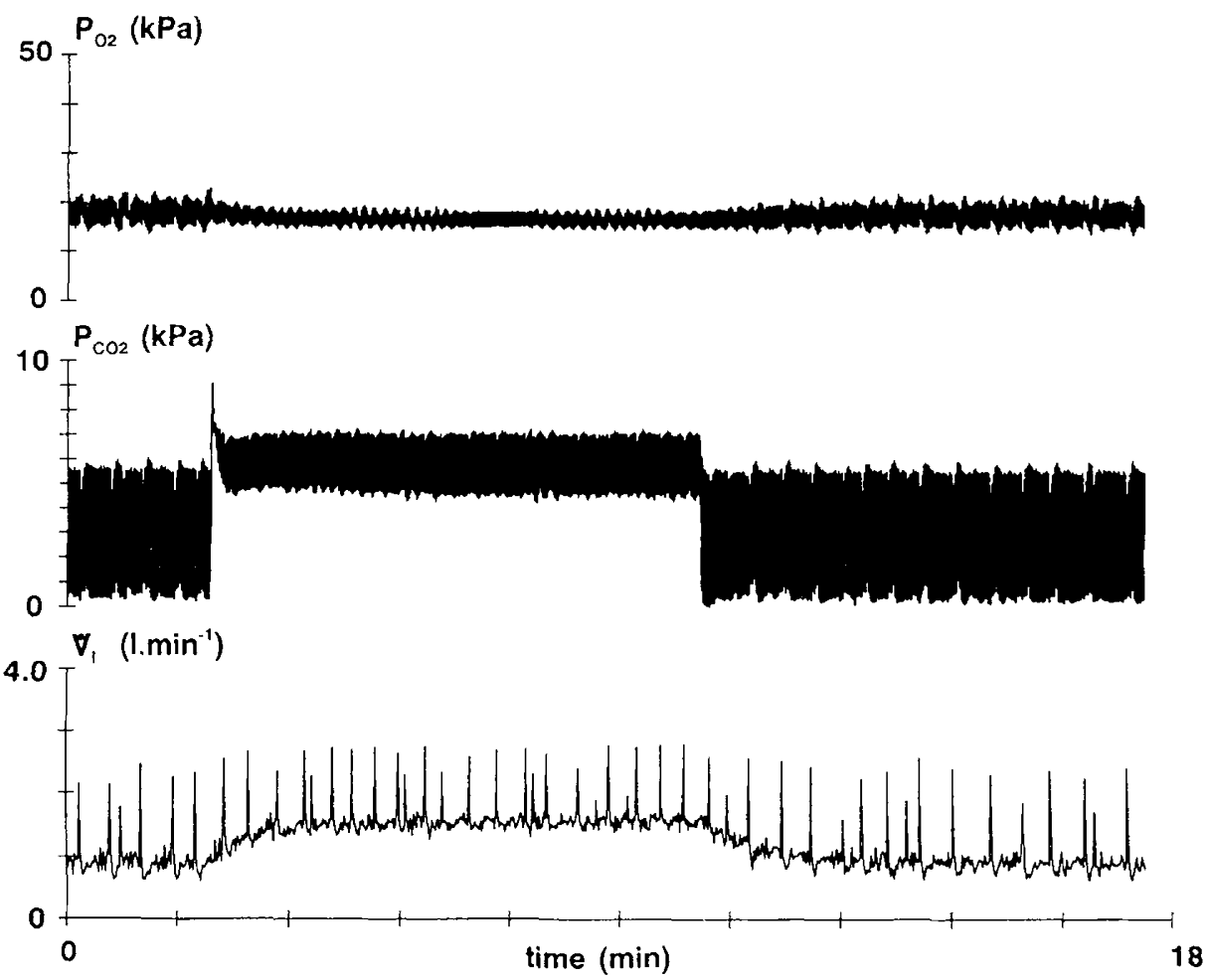

Fig. 1. Computer plot of breath-to-breath ventilation, $\mathrm{PO}_{2}$, and $\mathrm{PCO}_{2}$ (in tracheal gas) during a DEF experiment of a 3-d-old piglet. The PETO $\left(15 \mathrm{kPa}\right.$ ) was held constant throughout the experiment by servo-control continually adjusting the inspired $\mathrm{O}_{2}$ fraction. At the beginning and the end of the trace, $\mathrm{PETCO}_{2}$ was about $5.6 \mathrm{kPa}$. The step increase was $1.5 \mathrm{kPa}$.

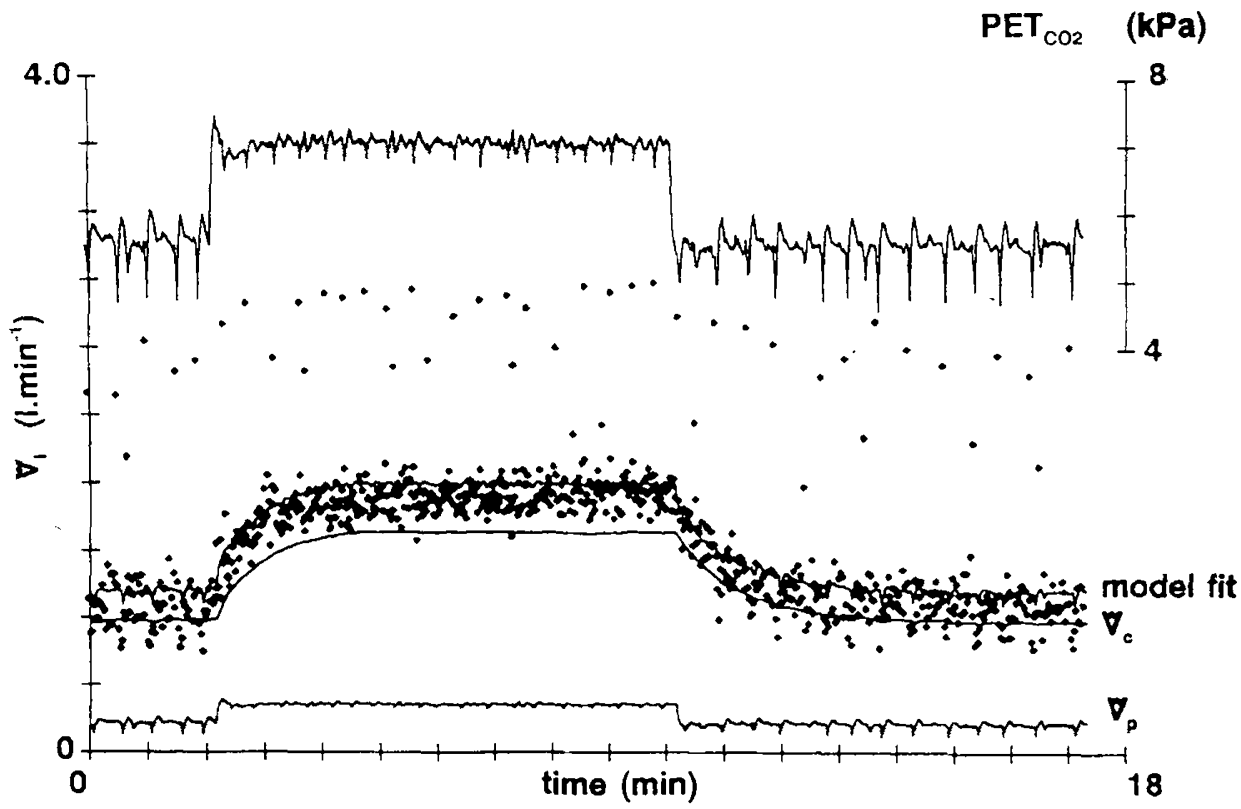

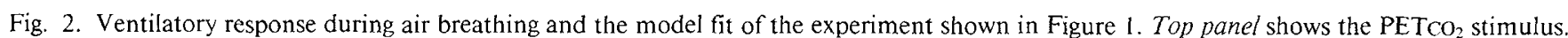
The dots represent the breath-to-breath ventilation. The curve through the data points is the model fit, minute ventilation $\left(\dot{V}_{I}\right)$. It is the sum of the slow $\left(\dot{V}_{c}\right)$ and the fast $\left(\dot{V}_{r}\right)$ components and a drift term, C.t (not shown separately). The estimated parameter values are: $\mathrm{B}, 3.36 \mathrm{kPa} ; \mathrm{S}_{c}, 199 \mathrm{~mL}$. $\mathrm{min}^{-1} \cdot \mathrm{kPa}^{-1} \cdot \mathrm{kg}^{-1} ; \mathrm{S}_{\mathrm{p}}, 43.3 \mathrm{~mL} \cdot \mathrm{min}^{-1} \cdot \mathrm{kPa}^{-1} \cdot \mathrm{kg}^{-1}$; central on-transient time constant, $38.7 \mathrm{~s}$; central off-transient time constant, $64.9 \mathrm{~s}$; peripheral time constant, $0.3 \mathrm{~s}$; central transport delay time, $4 \mathrm{~s}$; and peripheral transport delay time, $4 \mathrm{~s}$.

estimated $\mathrm{CO}_{2}$ sensitivity of the slow component corresponds to that of the central chemoreflex loop and the $\mathrm{CO}_{2}$ sensitivity of the fast one to that of the peripheral chemoreflex loop.

Using the DEF technique, we found that in piglets aged 2-12 $\mathrm{d}$ the peripheral chemoreceptors contribute appreciably to the ventilatory response to $\mathrm{CO}_{2}$ during air breathing. It is interesting to remark that piglets 3-9 d of age and 2-d-old lambs showed a high mortality in the days after carotid body denervation, sug- gesting an essential role for these receptors in the control of breathing at this stage of life $(18,19)$. The values found for the time constants and the ratio $S_{\mathrm{p}} / \mathrm{S}$ are similar to those found in adult anesthetized cats (12) and awake human beings (14). The delay times (central and peripheral transport) have values to be expected for the transmission of the disturbance in $\mathrm{CO}_{2}$ from the lungs to the sites of peripheral and central chemoreception. The $B$ value is lower than in cat and man and might indicate that a 

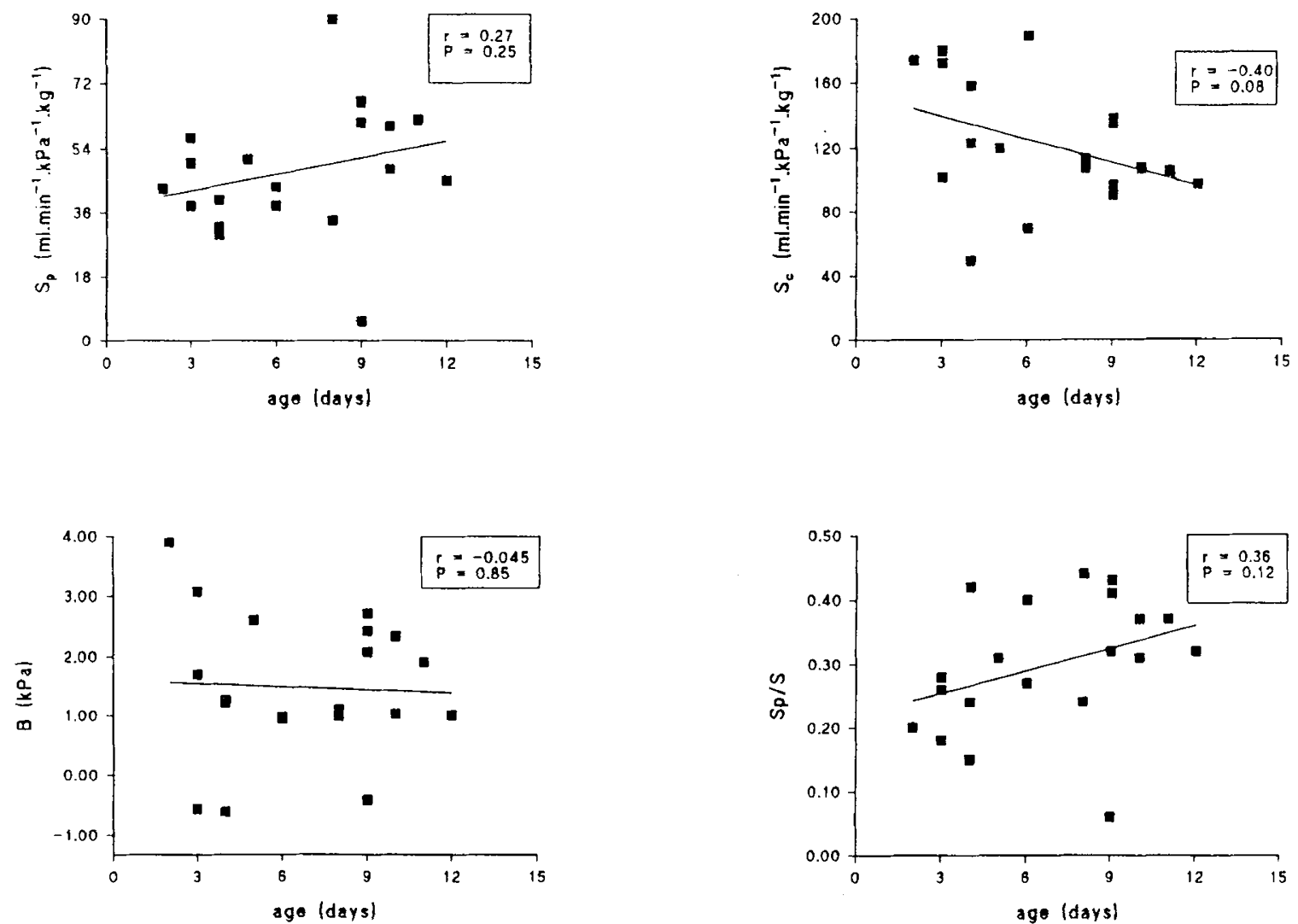

Fig. 3. The relationship between four estimated model parameters and age. No significant correlation could be found between $S_{p}, S_{c}, B$, and $S_{p} /$ $S$ versus age. The correlation coefficients together with the $p$ values are shown. Note that there are coinciding points. In the left upper panel, the upper point at $9 \mathrm{~d}$; the right upper panel, the point at $10 \mathrm{~d}$; the lower left panel, the point at $6 \mathrm{~d}$ and the upper point at $4 \mathrm{~d}$.

Table 1. Mean parameters for the DEF experiments (76 runs, 20 piglets)*

\begin{tabular}{lc}
\hline Parameter & DEF values \\
\hline $\mathrm{S}_{\mathrm{c}}\left(\mathrm{mL} \cdot \mathrm{min}^{-1} \cdot \mathrm{kPa}^{-1} \cdot \mathrm{kg}^{-1}\right)$ & $122 \pm 37.3$ \\
$\mathrm{~S}_{\mathrm{p}}\left(\mathrm{mL} \cdot \mathrm{min}^{-1} \cdot \mathrm{kPa}^{-1} \cdot \mathrm{kg}^{-1}\right)$ & $48.0 \pm 17.8$ \\
$\mathrm{~S}_{\mathrm{p}} / \mathrm{S}$ & $0.30 \pm 0.10$ \\
$\mathrm{~B}(\mathrm{kPa})$ & $1.48 \pm 1.19$ \\
$\tau_{\text {on }}(\mathrm{s})$ & $69.7 \pm 23.4$ \\
$\tau_{\text {orl }}(\mathrm{s})$ & $119 \pm 51.8$ \\
$\tau_{\mathrm{p}}(\mathrm{s})$ & $2.5 \pm 3.7$ \\
$\mathrm{~T}_{\mathrm{c}}(\mathrm{s})$ & $5.8 \pm 1.7$ \\
$\mathrm{~T}_{\mathrm{p}}(\mathrm{s})$ & $3.9 \pm 0.7$ \\
\hline
\end{tabular}

* Values are means of the means per piglet \pm SD. $\tau_{\text {on }}$, central ontransient time constant; $\tau_{\text {ofr }}$, central off-transient time constant; $\tau_{\mathrm{p}}$, peripheral time constant, $\Upsilon_{c}$, central transport delay time; and $T_{p}$, peripheral transport delay time.

$\mathrm{CO}_{2}$-independent ventilatory drive in the young piglet is present. There was no change in $B$ with age in contradistinction to the findings in 2- to 21-d-old monkeys (8). The correlation between the other estimated parameters and age was also not significant, although there was a tendency of $S_{p}$ to increase and $S_{c}$ to decrease.

Throughout each DEF experiment, the $\mathrm{PETO}_{2}$ was held at a level of $15 \mathrm{kPa}$, comparable to air breathing. Continuous measurement of the $\mathrm{PaO}_{2}$ in 11 piglets showed appreciable $\mathrm{PET}_{\mathrm{O}_{2}-}$ $\mathrm{PaO}_{2}$ gradients, especially in the piglets of younger age. If there is positive interaction in the ventilatory response between peripheral hypoxia and hypercapnia like in the cat (20), the peripheral chemoreceptors may be more stimulated in younger piglets because of the lower $\mathrm{PaO}_{2}$ values. It may well be that when the $\mathrm{PaO}_{2}$ of the piglets are matched an age-related effect on $\mathrm{S}_{\mathrm{p}}$ becomes more apparent. This point deserves further investigation.
The tendency of the central chemosensitivity $\left(S_{c}\right)$, normalized to body weight, to decrease with age might be due to the level of anesthesia. To obtain an adequate level of anesthesia, the total amount of anesthetics per $\mathrm{kg}$ body weight supplied to older animals was larger than to younger ones. Anesthesia is known to depress the ventilatory sensitivity to $\mathrm{CO}_{2}$. In studies in the cat $(21,22)$, we have found that, although at deeper levels of anesthesia the total slope is decreased, the peripheral and central $\mathrm{CO}_{2}$ sensitivities are decreased to the same extent so that the ratio $S_{p} /$ $\mathrm{S}$ was independent of the level of anesthesia. We investigated in seven piglets the effects of an additional dose of the anesthetics of $0.5 \mathrm{mg} \cdot \mathrm{kg}^{-1}$ zolazepam and tiletamine and $5 \mathrm{mg} \cdot \mathrm{kg}^{-1}$ chloralose with $25 \mathrm{mg} \cdot \mathrm{kg}^{-1}$ urethane. The overall ventilatory $\mathrm{CO}_{2}$ sensitivity decreased about $50 \%$, but like in the cat there was no systematic change in the ratio $S_{p} / S$ (Fig. 4 ). This suggests that also in the young piglet the ratio $S_{p} / S$ is independent of the level of anesthesia. The ratio $S_{p} / S$ is, therefore, an interesting quantity because it is not sensitive to the level of anesthesia and, furthermore, it is independent of the way of normalization to the size of the piglet.

Studies in the lamb suggest that after the initial resetting to hypoxia in the first $2 \mathrm{~d}$ after birth the maturation of the peripheral chemoreceptors continues up to $10 \mathrm{~d}$ of life $(6,7)$. In our piglets we could not obtain a significant correlation between the peripheral contribution to the ventilatory response to $\mathrm{CO}_{2}$ and age although $S_{p}$ over $S$ tended to increase with age. In one 9-d-old piglet, we could not detect a peripheral component in two of the three DEF runs. This finding might indicate nonfunctional peripheral chemoreceptors in this particular piglet. When the $S_{p} / S$ value of this piglet was considered as an exception and left out of the statistical analysis, the correlation between $\mathrm{S}_{\mathrm{p}} / \mathrm{S}$ and age became significant ( $r=0.55, p=0.01$ ).

This study describes the first quantitative measurements of the contribution of the peripheral and central chemoreflex loop to 


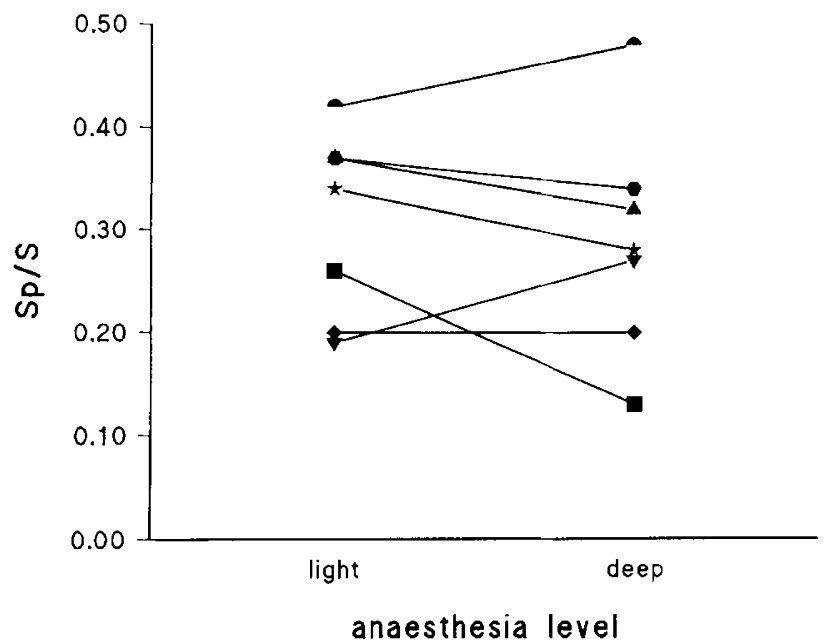

Fig. 4. $\mathrm{S}_{\mathrm{p}} / \mathrm{S}$ at two levels of anesthesia (light and deep).

the ventilatory response to $\mathrm{CO}_{2}$ during air breathing in young animals. Using the DEF technique, we have shown that the contribution of the peripheral chemoreceptors to this response is appreciable in 2- to 12-d-old piglets. Within this range of age, we could not demonstrate an age-related effect on the peripheral contribution. It would be interesting to use the DEF technique in piglets of younger age to investigate whether there is a change in sensitivity to $\mathrm{CO}_{2}$ of the peripheral and central chemoreceptors immediately after birth, as is the case for the $\mathrm{O}_{2}$ sensitivity of the peripheral chemoreceptors.

Acknowledgment. The authors thank L. Philips for his technical assistance.

\section{REFERENCES}

1. Hertzberg $\Upsilon$, Hellström S, Lagercrantz H, Pequignot 1990 Development of the arterial chemoreflex and turnover of carotid body catecholamines in the newborn rat. I Physiol (Lond) 425:211-225

2. Blanco CE, Dawes GS, Hanson MA, McCooke HB 1984 The response to hypoxia of arterial chemoreceptors in fetal sheep and newborn lambs. J Physiol (Lond) 351:25-37

3. Hanson MA, Kumar P, Williams BA 1989 The effect of chronic hypoxia upon the development of respiratory chemoreflexes in the newborn kitten. I Physiol (Lond) 411:563-574

4. Hanson MA 1986 Maturation of the peripheral chemoreceptor and central nervous components of respiratory control in perinatal life. In: von Euler C, Lagercrantz H (eds) Neurobiology of the Control of Breathing. Raven Press, New York, pp 59-65

5. Kumar P, Hanson MA 1989 Re-setting of the hypoxic sensitivity of aortic chemoreceptors in the newborn lamb. J Dev Physiol 11:199-206

6. Belenkey DA, Standaert TA, Woodrum DE 1979 Maturation of the hypoxic ventilatory response of the newborn lamb. J Appl Physiol 47:927-930

7. Bureau MA, Bégin R 1982 Postnatal maturation of the respiratory response to $\mathrm{O}_{2}$ in awake newborn lambs. J Appl Physiol 52:428-433

8. Purves MJ 1966 The respiratory response of the newborn lamb to inhaled $\mathrm{CO}_{2}$ with and without accompanying hypoxia. J Physiol (Lond) 185:78-94

9. Guthrie RD, Standaert TA, Hodson WA, Woodrum DE 1980 Sleep and maturation of eucapnic ventilation and $\mathrm{CO}_{2}$ sensitivity in the premature primate. J Appl Physiol 48:347-354

10. Rigatto HR, Brady JP, Chir B, De La Torre Verduzco R 1975 Chemoreceptor reflexes in preterm infants: II. The effect of gestational and postnatal age on the ventilatory response to inhaled carbon dioxide. Pediatrics 55:614-620

11. Swanson GD, Bellville JW 1975 Step changes in end-tidal $\mathrm{CO}_{2}$ : methods and implications. J Appl Physiol 39:377-385

12. DeGoede J, Berkenbosch A, Ward DS, Bellville JW, Olievier CN 1985 Comparison between chemoreflex gains from dynamic end-tidal $\mathrm{CO}_{2}$ forcing and artificial brain stem perfusion. J Appl Physiol 59:170-179

13. Bellville JW, Whipp BJ, Kaufman RD. Swanson GD, Aqleh KA, Wiberg DM 1979 Central and peripheral chemoreflex loop gain in normal and carotid body-resected subjects. J Appl Physiol 46:843-853

14. Dahan A, DeGoede J, Berkenbosch A, Olievier ICW 1990 The influence of oxygen on the ventilatory response to carbon dioxide in man. J Physiol (Lond) 428:485-499

15. Berkenbosch A, Heeringa J, Olievier CN, Kruyt EW 1979 Artificial perfusion of the ponto-medullary region of cats. A method for separation of central and peripheral effects of chemical stimulation of ventilation. Respir Physiol 37:347-364

16. Bryan CA. Bowes G. Maloney JE 1986 Control of breathing in the fetus and the newborn. In: Fishman AP. Cherniack NS, Widdicombe JG. Geiger SR (eds) Handbook of Physiology, Section 3, The Respiratory System. Vol II. American Physiological Society, Bethesda. MD, pp 621-647

17. Walker DW 1984 Peripheral and central chemoreceptors in the fetus and newborn. Annu Rev Physiol 46:687-703

18. Bureau MA, Lamarche J, Foulon P, Dalle D 1985 Postnatal maturation of respiration in intact and carotid body-denervated lambs. $J$ Appl Physiol 59:869-874

19. Donnelly DF, Haddad GG 1990 Prolonged apnea and impaired survival in piglets after sinus and aortic nerve section. J Appl Physiol 68:1048-1052

20. VanBeek JHGM, Berkenbosch A, DeGoede J, Olievier CN 1983 Influence of peripheral $\mathrm{O}_{2}$ tension on the ventilatory response to $\mathrm{CO}_{2}$ in cats. Respir Physiol 51:379-390

21. Berkenbosch A, DeGoede J. Olievier CN, Quanjer PhH 1982 Sites of action of halothane on respiratory pattern and ventilatory response to $\mathrm{CO}_{2}$ in cats Anesthesiology 57:389-398

22. Heeringa J. DeGoede J. Berkenbosch A. Olievier CN 1980 Influence of the depth of anaesthesia on the peripheral and central ventilatory $\mathrm{CO}_{2}$ sensitivity during hyperoxia. Respir Physiol 41:333-347 